\title{
Impact of Therapy Sequence with Alkylating Agents and MGMT Status in Patients with Advanced Neuroendocrine Tumors
}

\author{
SEBASTIAN KRUG ${ }^{1,2}$, MICHAEL BOCH $^{2}$, PETER REXIN ${ }^{3}$, \\ THOMAS M. GRESS ${ }^{2}$, PATRICK MICHL ${ }^{1}$ and ANJA RINKE ${ }^{2}$ \\ ${ }^{1}$ Department of Internal Medicine I, Martin Luther University Halle-Wittenberg, Halle (Saale), Germany; \\ ${ }^{2}$ Department of Gastroenterology and Endocrinology, Philipps-University, Marburg, Germany; \\ ${ }^{3}$ Institute of Pathology, Philipps-University, Marburg, Germany
}

\begin{abstract}
Background/Aim: Alkylating chemotherapeutics with either a streptozotocin-(STZ) or temozolomide-(TEM) backbone are routinely used in patients with progressive and unresectable pancreatic neuroendocrine tumors (PNET). In addition, dacarbazine (DTIC) was described as an alternative alkylating therapy option for PNETs. The optimal treatment sequence with alkylating compounds and a potential use of O6-methylguanine-DNA methyltransferase (MGMT) level as predictive biomarker have not yet been sufficiently elucidated. The aim of our study was the evaluation of therapy sequence with either STZ-based treatment followed by DTIC (group A) or the inverse schedule with upfront DTIC (group B) and to correlate MGMT status with clinicopathological characteristics and response to therapy. Patients and Methods: We retrospectively analyzed 28 patients with neuroendocrine tumors (NET) who were treated with STZbased therapy and DTIC. Additionally, in a second group MGMT immunohistochemistry was performed from primary and metastatic tumor sites. For statistical evaluation Kaplan-Meier analysis, Cox regression methods and Fisher's exact test were used. Results: There was no difference of objective response and disease control between either STZbased therapy followed by DTIC treatment (group A) after progression or the reverse sequence (group B). Median time to progression (TTP) was estimated to be 21 months in both arms. First-line STZ-based chemotherapy was not superior to first-line DTIC treatment ( 16 vs. 13 months; $p=0.8$ ). MGMT status did not correlate with clinicopathological
\end{abstract}

Correspondence to: Prof. Patrick Michl, Martin Luther University Halle-Wittenberg, Department of Internal Medicine I, Ernst-GrubeStr. 40, 06120 Halle (Saale), Germany. Tel: +49 3455572661, Fax: +49 3455572253, email: patrick.michl@uk-halle.de

Key Words: Sequence, DTIC, STZ, MGMT, neuroendocrine. characteristics or response to therapy with these alkylating agents. Conclusion: Upfront chemotherapy with either STZbased treatment or DTIC monotherapy showed similar efficacy and median TTP rates. In this study, MGMT protein expression assessed by immunohistochemistry did not play an important role as a predictive marker for alkylating agents.

Pancreatic neuroendocrine tumors (PNET) represent a rare and heterogenous disease, accounting for approximately 5\% of all pancreatic neoplasms $(1,2)$. While symptoms often occur late, the majority of PNET patients present with metastatic disease in up to $80 \%$ of cases $(3,4)$. Surgery remains the standard treatment for localized stages. In case of unresectable and metastatic disease medical treatment has been shown to improve the long-term outcome of patients. Recently, biotherapy with lanreotide demonstrated a benefit for PNET patients with Ki-67 values less than $10 \%$. In this trial, however, most patients had stable disease prior to start of treatment (96\%) and thus only reflect a subgroup of patients (5). For this reason the current guidelines of ENETS (European Neuroendocrine Tumor Society), NANETS (North American Neuroendocrine Tumor Society) and NCCN (National Comprehensive Cancer Network) recommend cytotoxic chemotherapy for patients with well-differentiated pancreatic neuroendocrine tumors and rapid tumor progress, symptomatic disease or high tumor load (6). In contrast to other neuroendocrine malignancies, PNETs are relatively chemosensitive. However, due to the limited number of randomized trials the value of chemotherapy is not well defined. Cytotoxic chemotherapy regimens commonly include alkylating agents such as streptozotocin (STZ), temozolomide (TEM) and dacarbazine (DTIC), with STZ and TEM commonly administered in combination with the antimetabolites 5-FU and capecitabine (CAP), respectively $(7,8)$. Overall, first-line chemotherapy with STZ plus 5-FU can achieve response rates up to $40 \%$ and progression-free 
survival times up to 20 months (9-13). Besides chemotherapy, a plethora of therapeutic options is available in advanced PNET patients. Loco-ablative and loco-regional approaches may affect a predominantly localized liver burden. Further systemic options include targeted therapies such as sunitinib and everolimus or the peptide receptor radionuclide therapy (PRRT). The latter has previously shown significant antitumor efficacy in midgut NET and was superior compared to somatostatin analogues SSA monotherapy (14). It is an ongoing debate how to select patients for the best treatment and sequence. To date, no comparative prospective trials are available which address the optimum therapy sequence. Currently, multiple alkylating agents in different therapeutic lines are frequently used, but evidence on their efficacy in sequential approaches is limited.

The mechanism of action by which alkylating agents affect tumor cells is based on diverse pathways. In this context the expression of the DNA repair enzyme $\mathrm{O}^{6}$ methylguanine DNA methyltransferase (MGMT) has been suggested as main regulator of sensitivity to alkylating drugs. MGMT protein is essential for genomic stability and can prevent DNA replication or mismatch errors on position $\mathrm{O}^{6}$ (15). Decreased MGMT activity might therefore be associated with enhanced effectiveness of alkylating compounds. MGMT detection can be achieved either with MGMT protein assessment via immunohistochemistry or by analysis of the MGMT promoter methylation status via PCR. There are no consistent data about correlation of protein and promoter methylation status in neuroendocrine neoplasms. However, recent studies have suggested an association of MGMT status and treatment with STZ or DTIC $(16,17)$.

The purpose of our study was to explore the efficacy of sequential treatment of STZ-based combination treatment followed by DTIC monotherapy or the reversed order in patients with advanced neuroendocrine tumors. Additionally, MGMT protein expression was assessed via immunohistochemistry to determine its prognostic or predictive impact in our cohort.

\section{Patients and Methods}

Patients. Patients $(\mathrm{n}=28)$ with histologically confirmed neuroendocrine tumors who received either STZ-based combination chemotherapy followed by DTIC (dacarbazine) monotherapy or the reversed sequence were retrospectively identified from a database at the comprehensive cancer center at the university hospital of Marburg. This study was conducted in accordance with the Declaration of Helsinki. Collection, storage, and evaluation of patient-related information in our neuroendocrine tumor (NET) database were performed after informed consent and with the approval of the local ethics committee at the university of Marburg.

Protocol treatment. Chemotherapy was applied either as combination therapy using STZ in combination with doxorubicine (Dox) or 5fluorouracil (5-FU) or as dacarbazine (DTIC) monotherapy. The chemotherapeutic STZ/Dox regimen included STZ at a dose of 500 $\mathrm{mg} / \mathrm{m}^{2}$ on days $1-5$ and Dox at a dose of $50 \mathrm{mg} / \mathrm{m}^{2}$ on day 1 and 22 . The regimen was repeated every 6 weeks. The STZ/5-FU regimen included short-term infusion of $5-\mathrm{FU}$ at a dose of $400 \mathrm{mg} / \mathrm{m}^{2}$ on days $1-5$, in addition to STZ every 6 weeks. Dox was terminated after 5 cycles (before reaching the cumulative dose of $550 \mathrm{mg} / \mathrm{m}^{2}$ ) and replaced by 5 -FU. DTIC was given as short-term infusion at a dose of $650 \mathrm{mg} / \mathrm{m} 2$ every 4 weeks.

Follow up and evaluation of tumor response. Follow-up investigations were scheduled after three completed treatment courses and included history, physical examination, laboratory investigations and imaging (CT or MRI scan). Response to treatment was evaluated using the international criteria proposed by the Response Evaluation Criteria in Solid Tumors (RECIST) Committee (18).

Evaluation of MGMT status in paraffin-embedded tissues. A total of 24 tissue samples were available from an independent cohort of consecutive patients treated either with STZ combinations or DTIC, including 20 PNET patients and 4 non-PNET patients treated at the Marburg ENETS center (Table I). Paraffin sections $(4 \mu \mathrm{m})$ were used for immunohistochemical analyses which were performed as described previously (16). The tissues were incubated with mouse monoclonal antibody to MGMT (dilution 1:25; Ab-1; clone MT 3.1; Thermo Scientific, Dreieich, Germany), a biotinylated secondary antibody (mouse $\operatorname{IgG}$ ), and subsequent visualization with avidinhorseradish peroxidase (Vectastain Elite ABC Kit; Vector Laboratories, Eching, Germany) according to the manufacturer's instructions.

Immunohistochemical MGMT expression was estimated independently by three investigators without knowledge of the clinical data. Nuclear MGMT expression was measured with the Remmele-Stegner immunoreactivity score (IRS), which is defined as product of nuclear staining intensity and number of positive cells (19). The results of the MGMT staining were categorized into deficient (score 0) and intact (score $>0$ ). Non-neoplastic cells (lymphocytes and endothelial cells) served as an internal positive control in all tissue sections. The MGMT expression status was then correlated with the clinical outcome of the patients.

Statistical design and analysis. The comparisons between clinical response and tumor characteristics, disease stage and laboratory features were based on Fisher's exact tests. Time to progression (TTP) was measured from the beginning of treatment to progression, death, or last follow-up. TTP was measured by the method of Kaplan and Meier (20). The statistical differences in TTP between groups of patients were estimated by the log-rank test (21). All statistical calculations were performed using SPSS (IBM SPSS Statistics). Differences were considered statistically significant when the $p$-value was less than 0.05 .

\section{Results}

Study population. Overall the study included 28 patients with advanced neuroendocrine tumors. Baseline characteristics are presented in Table II. Fifteen patients received STZ-based treatment followed by DTIC monotherapy (group A) and 13 patients received the reversed sequence (group B). Twenty-five patients suffered from a pancreatic NET, three patients $(\mathrm{n}=11 \%)$ 
Table I. Clinicopathological features of patients with MGMT analysis.

\begin{tabular}{|c|c|c|}
\hline Patient characteristics & $\begin{array}{l}\text { Number of patients } \\
\qquad(\mathrm{N}=24)\end{array}$ & $\%$ \\
\hline \multicolumn{3}{|l|}{ Gender } \\
\hline Female & 12 & 50 \\
\hline \multicolumn{3}{|c|}{ Age at diagnosis in years } \\
\hline Median (range) & $53(31-73)$ & \\
\hline \multicolumn{3}{|l|}{ Primary tumor } \\
\hline Pancreas & 20 & 83.3 \\
\hline Bronchus & 2 & 8.3 \\
\hline Gastric & 1 & 4.2 \\
\hline Midgut & 1 & 4.2 \\
\hline \multicolumn{3}{|l|}{ Tumor type } \\
\hline Non-functioning & 18 & 75 \\
\hline \multicolumn{3}{|l|}{ Differentiation } \\
\hline NET & 24 & 100 \\
\hline \multicolumn{3}{|l|}{ Grading } \\
\hline G1 & 2 & 8.3 \\
\hline $\mathrm{G} 2$ & 22 & 91.7 \\
\hline \multicolumn{3}{|l|}{ Sites of metastases } \\
\hline Lymph nodes & 13 & 54.2 \\
\hline Liver & 24 & 100 \\
\hline Bone & 4 & 16.7 \\
\hline \multicolumn{3}{|l|}{ Chemotherapy } \\
\hline DTIC only & 9 & 37.5 \\
\hline STZ-based only & 0 & 0 \\
\hline Both & 15 & 62.5 \\
\hline
\end{tabular}

STZ, Streptozotocin; DTIC, dacarbazine; NET, neuroendocrine tumor.

Table II. Baseline patient characteristics.

\begin{tabular}{|c|c|c|c|c|}
\hline \multirow{2}{*}{$\begin{array}{l}\text { Baseline patient } \\
\text { characteristics } \\
\text { Parameter }\end{array}$} & \multicolumn{2}{|c|}{$\begin{array}{c}\mathrm{STZ} \rightarrow \mathrm{DTIC} \\
\mathrm{N}=15 \\
\text { Group A }\end{array}$} & \multicolumn{2}{|c|}{$\begin{array}{c}\text { DTIC } \rightarrow \text { STZ } \\
\text { N=13 } \\
\text { Group B }\end{array}$} \\
\hline & $\mathrm{N}$ & $\%$ & $\mathrm{~N}$ & $\%$ \\
\hline \multicolumn{5}{|l|}{ Gender } \\
\hline Female & 7 & 47 & 7 & 54 \\
\hline \multicolumn{5}{|c|}{ Age at diagnosis in years } \\
\hline Median (range) & $52(35-70)$ & & $55(33-73)$ & \\
\hline \multicolumn{5}{|l|}{ Primary tumor } \\
\hline Pancreas & 12 & 80 & 13 & 100 \\
\hline Bronchus & 3 & 20 & & \\
\hline \multicolumn{5}{|l|}{ Tumor type } \\
\hline Non-functioning & 12 & 80 & 9 & 69 \\
\hline \multicolumn{5}{|l|}{ Differentiation } \\
\hline NET & 15 & 100 & 13 & 100 \\
\hline \multicolumn{5}{|l|}{ Grading } \\
\hline G1 & 2 & 13 & 2 & 15 \\
\hline $\mathrm{G} 2$ & 13 & 87 & 11 & 85 \\
\hline \multicolumn{5}{|l|}{ Sites of metastases } \\
\hline Lymph node & 7 & 47 & 8 & 62 \\
\hline Liver & 14 & 93 & 13 & 100 \\
\hline Bone & 6 & 40 & 4 & 31 \\
\hline
\end{tabular}

STZ, Streptozotocin; DTIC, dacarbazine; NET, neuroendocrine tumor.
Sequence of therapy



Figure 1. Time to progression (TTP) for the sequence streptozotocin (STZ) followed by dacarbazine (DTIC) $(N=15)$ or the reverse $(N=13)$. Median TTP was 21 months in both arms $(p=0.50)$.

had a bronchus NET. These three patients were all assigned to group A. In all other clinical parameters, the two treatment groups were well balanced including patient's age (median: 52 vs. 55 years), NET functionality (FNA: 80 vs. 69\%), grading (G2: 87 vs. 85\%) and sites of metastases (Table II).

Efficacy results. Median TTP was 21 months in both groups (HR 0.8, 95\% CI 0.4-1.7, $p=0.5$ ) (Figure 1). The objective response rate during first-line treatment was $47 \%$ for group A and $23 \%$ for group B $(p=0.25)$; corresponding disease control rates (objective response rate plus stable disease) were $87 \%$ and $62 \%$, respectively, (Table III) favoring firstline STZ, however, without significance $(p=0.2)$. Results for TTP after failure of 1st- or 2nd-line therapy demonstrated again a non-superiority of STZ over DTIC (Figure 2).

MGMT expression. A total of 24 tumor blocks were available for immunohistochemistry in patients treated with either DTIC monotherapy or STZ-based combination therapy. Baseline patient characteristics are listed in Table I. Among them, 20 tumors were of pancreatic and 4 of non-pancreatic origin. We additionally grouped the tissue samples of pancreatic NETs according to their anatomical origin in primary tumor tissues and specimens from hepatic metastases (Table IV). Among 24 patients with NETs, 15 $(62.5 \%)$ were MGMT deficient and 9 (37.5\%) MGMT intact 

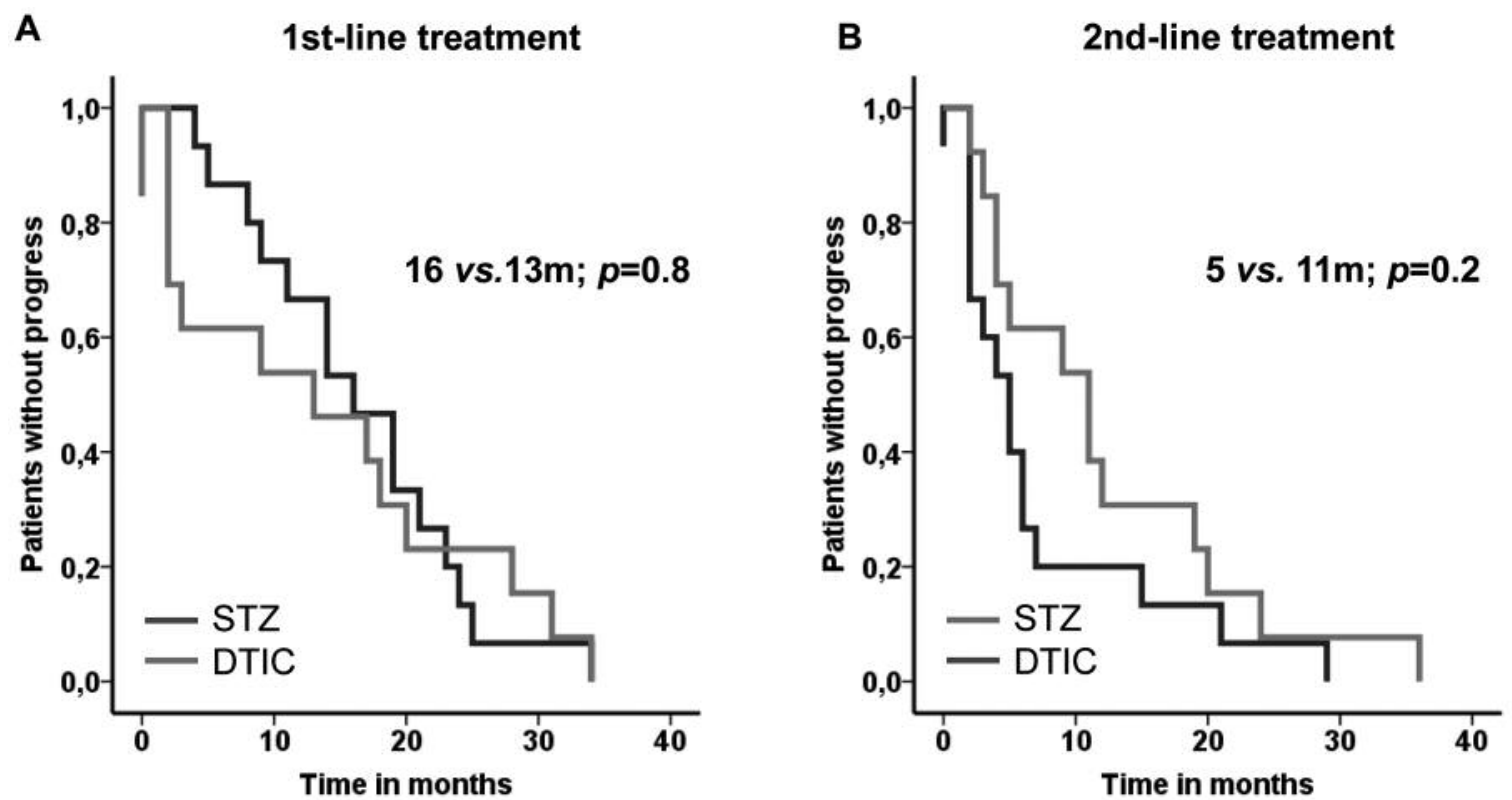

Figure 2. Median TTP for first- (A) and second-line (B) treatment. Streptozotocin (STZ) vs. dacarbazine (DTIC): 16 vs. 13 months (p=0.8) and DTIC vs. STZ: 5 vs. 11 months ( $p=0.2)$.

Table III. Treatment efficacy.

\begin{tabular}{lcccc}
\hline Treatment efficacy & \multicolumn{2}{c}{$\begin{array}{c}\text { STZ } \rightarrow \text { DTIC } \\
\text { N=15 }\end{array}$} & \multicolumn{2}{c}{$\begin{array}{c}\text { DTIC } \rightarrow \text { STZ } \\
\text { N=13 }\end{array}$} \\
\cline { 2 - 5 } Parameter & $\mathrm{N}$ & $\%$ & $\mathrm{~N}$ & $\%$ \\
\hline 1st-line patients & & & & \\
$\quad$ Complete response & 0 & 0 & 0 & 0 \\
Partial response & 7 & 47 & 3 & 23 \\
Stable disease & 6 & 40 & 5 & 38.5 \\
Progressive disease & 2 & 13 & 5 & 38.5 \\
2st-line patients & & & & \\
$\quad$ Complete response & 0 & 0 & 0 & 0 \\
Partial response & 5 & 33 & 5 & 38 \\
Stable disease & 4 & 27 & 2 & 16 \\
Progressive disease & 6 & 40 & 6 & 46 \\
\hline
\end{tabular}

STZ, Streptozotocin; DTIC, dacarbazine.

(Figure 3). Absence of MGMT staining was observed in 11 of 20 PNETs $(55 \%)$ and all 4 non-PNETs (100\%). In contrast, MGMT expression was present in 9 of 20 PNETs (45\%). Of the 20 patients with PNETs we analyzed primary tumor tissues from 6 patients and liver metastases from 14 patients. Five $(83.3 \%)$ of 6 primary tumors were MGMT deficient and $1(16.7 \%)$ revealed a positive staining. In addition, $6(42.9 \%)$ of 14 liver metastases exhibited no MGMT staining, $8(57.1 \%)$ were positive. There was no
Table IV. Correlation of MGMT status to tumor site

\begin{tabular}{lccc}
\hline Patient characteristics & $\begin{array}{c}\text { Number } \\
\text { of patients } \\
(\%)\end{array}$ & $\begin{array}{c}\text { MGMT } \\
\text { deficient } \\
\mathrm{n}(\%)\end{array}$ & $\begin{array}{c}\text { MGMT } \\
\text { intact } \\
\mathrm{n}(\%)\end{array}$ \\
\hline PNET & $20(100)$ & $11(55)$ & $9(45)$ \\
$\quad$ Primary site & $6(30)$ & $5(83.3)$ & $1(16.7)$ \\
Liver site & $14(70)$ & $6(42.9)$ & $8(57.1)$ \\
Non-PNET & $4(100)$ & $4(100)$ & 0 \\
Bronchus & $2(50)$ & $2(50)$ & \\
Gastric & $1(25)$ & $1(25)$ & \\
Midgut & $1(25)$ & $1(25)$ & 9 \\
All NET & 24 & 15 & 9 \\
\hline
\end{tabular}

MGMT, O6-Methylguanine-DNA methyltransferase; PNET, pancreatic neuroendocrine tumor; NET, neuroendocrine tumor.

statistical correlation of the MGMT status with PNETs versus non-PNETs or primary versus liver metastatic site. In conclusion, no correlation between patient characteristics and MGMT status was detected (Table V).

Clinical correlation of patients treated with DTIC and STZ to the MGMT status. Overall, 39 treatments with either DTIC or STZ were assessable. Among them, 24 patients were treated with DTIC (9 DTIC only) and additionally 15 patients received 
MGMT



Figure 3. Representative immunohistochemistry of MGMT in liver metastases in 20-fold magnification.

STZ-based therapy during disease progression. In the DTIC group $8(30.8 \%)$ patients had an objective response (PR), all of pancreatic origin. In the PNET cohort, 4 (57.1\%) patients with an objective response revealed an MGMT-deficient tumor, whereas the remaining 4 tumors $(30.8 \%)$ revealed a positive MGMT staining. For STZ-based therapy objective response was achieved in 7 patients $(46.7 \%)$, and in 5 of the 7 patients MGMT expression was intact (55.6\%). Of 5 patients with progressive disease, 2 (40\%) had no MGMT expression. Neither response to DTIC nor to STZ-based treatment showed a statistically significant correlation to MGMT status (Table VI). Moreover, MGMT status had no impact on progressionfree survival for all or PNET only patients (Figure 4) and was not related to DTIC or STZ first-line therapy (Figure 5).

\section{Discussion}

Our study indicated that both investigated sequential therapeutic approaches were equally effective regarding mTTP. Whereas no trend was measured after first-line
Table V. Correlation of MGMT status to baseline patient characteristics.

\begin{tabular}{|c|c|c|c|c|}
\hline $\begin{array}{l}\text { Patient } \\
\text { characteristics }\end{array}$ & $\begin{array}{l}\text { Number } \\
\text { of patients } \\
(\mathrm{N}=24)\end{array}$ & $\begin{array}{l}\text { MGMT } \\
\text { intact }\end{array}$ & $\begin{array}{l}\text { MGMT } \\
\text { deficient }\end{array}$ & $\begin{array}{c}p \text {-Value } \\
\text { (Fisher's } \\
\text { exact test) }\end{array}$ \\
\hline \multicolumn{5}{|l|}{ Gender } \\
\hline Female & 12 & 5 & 7 & \multirow[t]{2}{*}{0.41} \\
\hline Male & 12 & 8 & 4 & \\
\hline \multicolumn{5}{|l|}{ Age in years } \\
\hline$<60$ & 17 & 10 & 7 & \multirow[t]{2}{*}{0.66} \\
\hline$\geq 60$ & 7 & 3 & 4 & \\
\hline \multicolumn{5}{|l|}{ Tumor Type } \\
\hline Non-functioning & 18 & 8 & 10 & \multirow[t]{2}{*}{0.17} \\
\hline Functioning & 6 & 5 & 1 & \\
\hline \multicolumn{5}{|l|}{ Grading } \\
\hline G1 & 6 & 3 & 3 & \multirow[t]{2}{*}{1.0} \\
\hline G2 & 18 & 10 & 8 & \\
\hline \multicolumn{5}{|l|}{$\mathrm{Ki}-67$} \\
\hline$<10 \%$ & \multirow[t]{2}{*}{13} & 9 & 4 & 0.22 \\
\hline$\geq 10 \%$ & & 11 & 4 & 7 \\
\hline \multicolumn{5}{|l|}{ SMS status } \\
\hline Negative & 2 & 1 & 1 & \multirow[t]{2}{*}{1.0} \\
\hline Positive & 18 & 11 & 8 & \\
\hline \multicolumn{5}{|l|}{ Sites of metastases } \\
\hline Liver+LN & 12 & 7 & 5 & \multirow[t]{2}{*}{0.71} \\
\hline +Other & 12 & 6 & 6 & \\
\hline
\end{tabular}

MGMT, $\mathrm{O}^{6}$-Methylguanine-DNA methyltransferase; LN, lymph nodes; SMS, somatostatin.

treatment between both groups, STZ-based therapy was superior in the second-line, however without reaching statistical significance. Overall patient characteristics were well balanced despite the retrospective nature of our study. However, the documentation of the performance status was incomplete in the medical records and thus not analyzable. We assume that only in patients with a very good performance status (PS) STZ combination treatment after failure of DTIC was feasible, possibly explaining the impact of STZ-based combination therapy in the second-line setting. The impact of PS on therapeutic decisions, treatment efficacy and patient outcome is well described (6), particularly for patients who are selected to undergo surgery despite metastatic disease. Resection of the primary tumor in midgut or pancreatic origin is associated with improved survival; however, only patients with an appropriate PS will be candidates for surgical resection (22-25).

Our data on treatment efficacy, as assessed by objective response and disease control are well in line with previously published studies $(11,12)$. Importantly, our study demonstrates that the switch to another alkylating agent after disease progression during first-line treatment induces objective responses in more than $30 \%$ of the patients. This effect was consistent in both treatment arms. Thus, in patients with high 

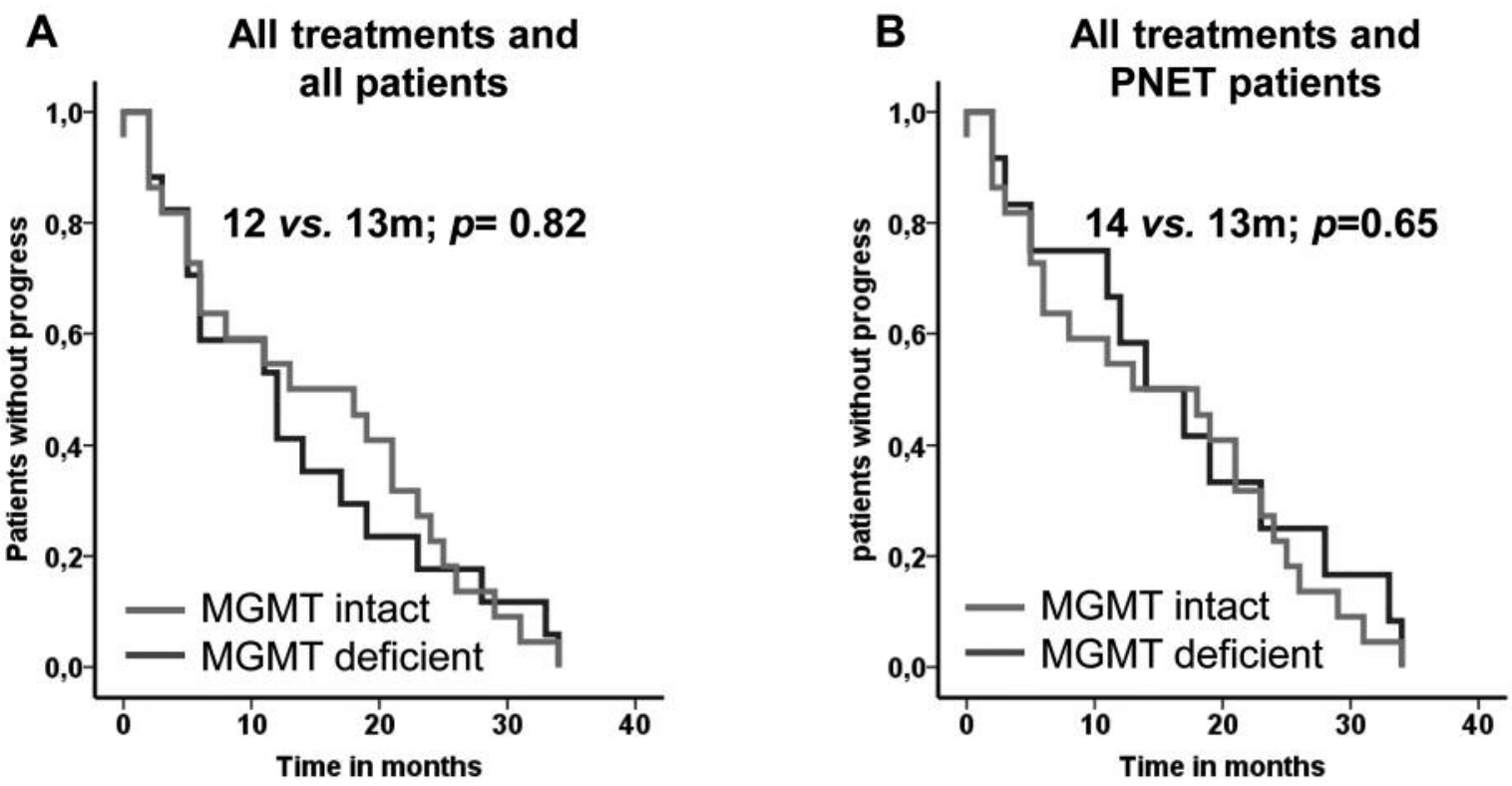

Figure 4. Kaplan-Meier curves on time to progression with respect to MGMT status (intact, deficient) and primary tumor site. For all patients (A) and only PNET patients $(B)$ no association was described. A: $12 \mathrm{vs} .13$ months ( $p=0.82)$. B: 14 vs. 13 months $(p=0.65)$.
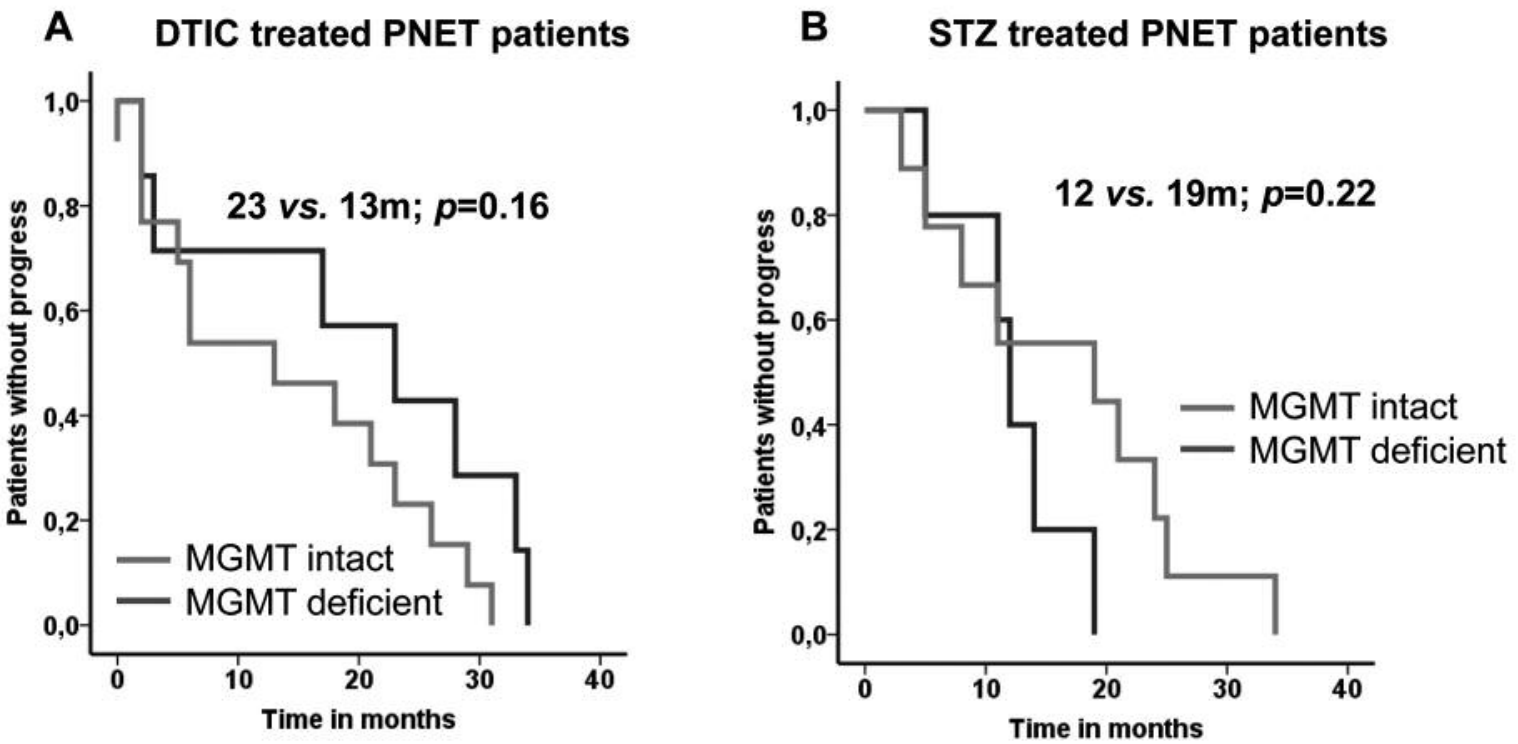

Figure 5. Impact of MGMT status (intact, deficient) on alkylating compound used. For DTIC treated PNET patients (A) and STZ-based treatment (B). A: 23 vs. 13 months ( $p=0.16)$. B: 12 vs. 19 months $(p=0.22)$.

tumor burden, symptomatic disease and remission pressure after progression of first-line chemotherapy, STZ combinations or DTIC monotherapy are relevant therapeutic options. Our data on therapy sequencing with alkylating agents provide a new concept for treatment in patients with advanced neuroendocrine tumors. Although several treatment options for
PNETs have been approved and are in clinical use, randomized phase III trials exist only for lanreotide, sunitinib and everolimus $(5,26,27)$. Based on former randomized trials and retrospective evaluations, STZ-based chemotherapy is recommended as the therapy of choice in metastatic disease (6). Since most patients will be treated for many years during 
Table VI. Correlation of MGMT status to treatment response.

\begin{tabular}{|c|c|c|c|c|c|c|c|c|}
\hline \multicolumn{4}{|c|}{ Correlation to response } & \multirow[b]{2}{*}{ ORR \% } & \multirow[b]{2}{*}{ DCR \% } & \multirow[b]{2}{*}{ Treatments } & \multicolumn{2}{|c|}{ Fisher's exact test ( $p$-value) } \\
\hline MGMT & PR & $\mathrm{SD}$ & $\mathrm{PD}$ & & & & OR & $\mathrm{DC}$ \\
\hline All & 15 & 12 & 12 & 38.5 & 69.2 & 39 & & \\
\hline Intact & 3 & 6 & 3 & 25.0 & 75.0 & 12 & 0.24 & 0.66 \\
\hline Deficient & 6 & 4 & 2 & 50.0 & 83.3 & 12 & & \\
\hline DTIC treated & 8 & 9 & 7 & 33.3 & 70.8 & 24 & & \\
\hline Intact & 4 & 6 & 3 & 30.8 & 76.9 & 13 & 1.0 & 0.66 \\
\hline Deficient & 4 & 3 & 4 & 36.4 & 63.6 & 11 & & \\
\hline STZ treated & 7 & 3 & 5 & 46.7 & 66.7 & 15 & & \\
\hline Intact & 5 & 1 & 3 & 55.6 & 66.7 & 9 & 0.61 & 1.0 \\
\hline Deficient & 2 & 2 & 2 & 33.3 & 66.7 & 6 & & \\
\hline DTIC PNET & 8 & 8 & 4 & 40.0 & 80.0 & 20 & & \\
\hline Intact & 4 & 6 & 3 & 30.8 & 76.9 & 13 & 0.36 & 0.66 \\
\hline Deficient & 4 & 2 & 1 & 57.1 & 85.7 & 7 & & \\
\hline STZ PNET & 7 & 3 & 4 & 50.0 & 71.4 & 14 & & \\
\hline Intact & 5 & 1 & 3 & 55.6 & 66.7 & 9 & 0.63 & 1.0 \\
\hline Deficient & 2 & 2 & 1 & 40.0 & 80.0 & 5 & & \\
\hline
\end{tabular}

MGMT, O6-Methylguanine-DNA methyltransferase; PNET, pancreatic neuroendocrine tumor; NET, neuroendocrine tumor; CR, complete response; $\mathrm{PR}=$ partial response; $\mathrm{SD}$, stable disease; PD, progressive disease; OR, objective response; DC, disease control.

the course of their disease $(4,28)$, most patients will be exposed to a broad variety of therapeutic approaches, including surgery, biotherapy, cytotoxic chemotherapy, loco-regional therapy, targeted therapies and peptide receptor radionuclide therapy (PRRT). It is noteworthy that no comparative trials on optimal therapy sequences are available yet. The SEQTOR trial is an ongoing evaluation of the best sequence of STZ/5-FU followed by everolimus versus the reverse sequence. Our study presents promising results about the efficacy of alkylating compounds in sequential therapies. However, these positive results have been acquired retrospectively and are not transferable to other sequential combinations.

As already known, targeted therapies mostly achieve disease stabilization in patients with advanced PNETs, however, induced resistance via multiple mechanisms occur potentially driving the disease more aggressive. Preclinical data have very well demonstrated the increase in the development of metastasis during antiangiogenic treatment (29-31). In this context the results of the European multicenter SEQTOR trial are urgently awaited. Furthermore, no studies comparing the impact of targeted therapies, chemotherapy, SSA or PRRT are available. Interestingly, one study is planned to compare PRRT and everolimus in nonresectable progressive and somatostatin receptor-positive PNET patients (COMPETE study). The clinical value of PRRT in advanced NETs was controversial and discussed for a long time, but the NETTER-1 results significantly indicated the superiority of PRRT with lutetium-177 (177Lu)-Dotatate over SSA monotherapy in terms of responses and PFS in midgut patients (14). If these data are reproducible in PNETs, then a comparison with targeted agents is warranted. Selecting the optimal therapeutic sequence for PNET patients also requires predictive markers for treatment stratification and patient selection. There are many studies investigating the potential value of MGMT expression or MGMT promoter methylation to predict outcome in patients treated with alkylating compounds. Our study showed no significant correlation between immunohistochemically-assessed MGMT expression and response to treatment or TTP, neither with STZ nor with DTIC. Alkylating agents such as temozolomide (TEM) and DTIC are frequently used in patients with glioblastomas and melanomas. In these entities MGMT promoter methylation was favorably linked to response $(32,33)$. Interestingly, many studies have clearly demonstrated that there is no correlation between MGMT protein expression and MGMT promoter methylation $(34,35)$, the mechanistic basis of this discrepancy still not being completely understood.

In advanced PNET patients, the impact of MGMT status also remains to be elucidated. Kulke et al. reported MGMT deficiency in $51 \%$ of PNET and $0 \%$ of carcinoid tumors, as assessed by immunohistochemistry. This could explain the long known fact that carcinoids frequently are not responsive to chemotherapy in contrast to PNET (16). However, other studies came up with more conflicting results, in particular concerning the frequency of MGMT promoter methylation $(36,37)$ and response to treatment $(38,39)$. Inhomogeneous patient cohorts and different therapy regimen may have 
complicated the evaluation. Very recently, Schmitt et al. published a large series of 141 resected PNETs tested for MGMT protein expression and MGMT promoter methylation (40). In a small subgroup they also investigated the correlation between MGMT protein expression, MGMT promoter methylation and response to TEM chemotherapy. As reported in previous studies, no correlation between MGMT protein expression and MGMT promoter methylation was found. Moreover, response to TEM was predicted by MGMT promoter methylation, but not by MGMT protein expression. Similar results were obtained by Cives et al. who described that MGMT expression failed to influence the effect of TEM (41). In addition, in a French cohort reported by Walter et al. pyrosequencing was used to assess MGMT promoter methylation status. In their study median PFS was significantly increased in patients with PNETs and methylated MGMT promoter. Multivariate analyses confirmed the benefit for STZ-based treatment and DTIC in this group (17).

Taken together, our data and the majority of reported data in the literature suggest that assessment of the MGMT status by immunohistochemistry is most likely not suitable to predict response to alkylating agents. Determining the methylation status of the MGMT promoter might be more promising according to literature, although also still under investigation. Prospective validation of the optimal detection method of the MGMT status as biomarker is urgently warranted to guide systemic therapy of PNET patients.

\section{Conclusion}

In conclusion, our findings indicate a role for sequential approaches with alkylating chemotherapeutics in patients with advanced PNETs. No statistically significant differences were found between STZ-based treatment followed by DTIC monotherapy or the reverse sequence. Both treatment schedules resulted in clinically-relevant objective response rates. MGMT status as assessed by immunohistochemistry failed to select patients for the optimal therapy and was no predictor for treatment efficacy. Further comparative clinical trials must be designed to assess the pivotal challenge of sequential treatment algorithms and to define predictive markers for those treatment strategies to improve the care for PNET patients.

\section{Conflicts of Interest}

The Authors declare that there is no conflict of interest that could be perceived as prejudicing the impartiality of the research reported.

\section{Ethics Approval and Consent to Participate}

This study was conducted in accordance with the Declaration of Helsinki. Collection, storage, and evaluation of patient-related information in our neuroendocrine tumor (NET) database were performed after informed consent and with the approval of the local ethics committee at the University of Marburg.

\section{Funding}

This work was funded by grants from the Behring-Roentgen Foundation and by an internal grant of the University Hospital Marburg.

\section{Acknowledgements}

The Authors are grateful to Svenja Diehl for database management.

\section{References}

1 Yao JC, Hassan M, Phan A, Dagohoy C, Leary C, Mares JE, Abdalla EK, Fleming JB, Vauthey JN, Rashid A and Evans DB: One hundred years after "Carcinoid": Epidemiology of and prognostic factors for neuroendocrine tumors in 35,825 cases in the united states. J Clin Oncol 26(18): 3063-3072, 2008.

2 Lawrence B, Gustafsson BI, Chan A, Svejda B, Kidd M and Modlin IM: The epidemiology of gastroenteropancreatic neuroendocrine tumors. Endocrinol Metab Clin North Am 40(1): 1-18, 2011.

3 Halfdanarson TR, Rabe KG, Rubin $\mathrm{J}$ and Petersen GM: Pancreatic neuroendocrine tumors (pnets): Incidence, prognosis and recent trend toward improved survival. Ann Oncol 19(10): 1727-1733, 2008.

4 Panzuto F, Boninsegna L, Fazio N, Campana D, Pia Brizzi M, Capurso G, Scarpa A, De Braud F, Dogliotti L, Tomassetti P, Delle Fave G and Falconi M: Metastatic and locally advanced pancreatic endocrine carcinomas: Analysis of factors associated with disease progression. J Clin Oncol 29(17): 2372-2377, 2011.

5 Caplin ME, Pavel M, Ćwikła JB, Phan AT, Raderer M, Sedláčková E, Cadiot G, Wolin EM, Capdevila J, Wall L, Rindi G, Langley A, Martinez S, Blumberg J, Ruszniewski P and Investigators $\mathrm{C}$ : Lanreotide in metastatic enteropancreatic neuroendocrine tumors. N Engl J Med 371(3): 224-233, 2014.

6 Pavel M, O'Toole D, Costa F, Capdevila J, Gross D, Kianmanesh R, Krenning E, Knigge U, Salazar R, Pape UF, Öberg K and participants VCC: Enets consensus guidelines update for the management of distant metastatic disease of intestinal, pancreatic, bronchial neuroendocrine neoplasms (nen) and nen of unknown primary site. Neuroendocrinology 103(2): 172-185, 2016.

7 Pavel M, Baudin E, Couvelard A, Krenning E, Öberg K, Steinmüller T, Anlauf M, Wiedenmann B, Salazar R and participants BCC: Enets consensus guidelines for the management of patients with liver and other distant metastases from neuroendocrine neoplasms of foregut, midgut, hindgut, and unknown primary. Neuroendocrinology 95(2): 157-176, 2012.

8 Öberg K, Knigge U, Kwekkeboom D, Perren A and Group EGW: Neuroendocrine gastro-entero-pancreatic tumors: Esmo clinical practice guidelines for diagnosis, treatment and followup. Ann Oncol 23(Suppl 7): vii124-130, 2012.

9 Kouvaraki MA, Ajani JA, Hoff P, Wolff R, Evans DB, Lozano $\mathrm{R}$ and Yao JC: Fluorouracil, doxorubicin, and streptozocin in the treatment of patients with locally advanced and metastatic pancreatic endocrine carcinomas. J Clin Oncol 22(23): 47624771, 2004. 
10 Fjallskog ML, Janson ET, Falkmer UG, Vatn MH, Oberg KE and Eriksson BK: Treatment with combined streptozotocin and liposomal doxorubicin in metastatic endocrine pancreatic tumors. Neuroendocrinology 88(1): 53-58, 2008.

11 Dilz LM, Denecke T, Steffen IG, Prasad V, von Weikersthal LF, Pape UF, Wiedenmann B and Pavel M: Streptozocin/5fluorouracil chemotherapy is associated with durable response in patients with advanced pancreatic neuroendocrine tumours. Eur J Cancer 51(10): 1253-1262, 2015.

12 Clewemar Antonodimitrakis P, Sundin A, Wassberg C, Granberg D, Skogseid B and Eriksson B: Streptozocin and 5-fu for the treatment of pancreatic neuroendocrine tumors: Efficacy, prognostic factors and toxicity. Neuroendocrinology 103(3-4): 345-53, 2015.

13 Krug S, Boch M, Daniel H, Nimphius W, Müller D, Michl P, Rinke A and Gress TM: Streptozocin-based chemotherapy in patients with advanced neuroendocrine neoplasms - predictive and prognostic markers for treatment stratification. PLoS One 10(12): e0143822, 2015.

14 Strosberg J, El-Haddad G, Wolin E, Hendifar A, Yao J, Chasen B, Mittra E, Kunz PL, Kulke MH, Jacene H, Bushnell D, O'Dorisio TM, Baum RP, Kulkarni HR, Caplin M, Lebtahi R, Hobday T, Delpassand E, Van Cutsem E, Benson A, Srirajaskanthan R, Pavel M, Mora J, Berlin J, Grande E, Reed N, Seregni E, Öberg K, Lopera Sierra M, Santoro P, Thevenet T, Erion JL, Ruszniewski P, Kwekkeboom D, Krenning E and Investigators N-T: Phase 3 trial of (177)lu-dotatate for midgut neuroendocrine tumors. N Engl J Med 376(2): 125-135, 2017.

15 Christmann M, Verbeek B, Roos WP and Kaina B: O(6)methylguanine-dna methyltransferase (mgmt) in normal tissues and tumors: Enzyme activity, promoter methylation and immunohistochemistry. Biochim Biophys Acta 1816(2): 179190, 2011.

16 Kulke MH, Hornick JL, Frauenhoffer C, Hooshmand S, Ryan DP, Enzinger PC, Meyerhardt JA, Clark JW, Stuart K, Fuchs CS and Redston MS: O6-methylguanine dna methyltransferase deficiency and response to temozolomide-based therapy in patients with neuroendocrine tumors. Clin Cancer Res 15(1): 338-345, 2009.

17 Walter T, van Brakel B, Vercherat C, Hervieu V, Forestier J, Chayvialle JA, Molin Y, Lombard-Bohas C, Joly MO and Scoazec JY: O6-methylguanine-dna methyltransferase status in neuroendocrine tumours: Prognostic relevance and association with response to alkylating agents. Br J Cancer 112(3): 523-531, 2015.

18 Duffaud F and Therasse P: New guidelines to evaluate the response to treatment in solid tumors. Bull Cancer 87(12): 881886,2000

19 Remmele W, Hildebrand U, Hienz HA, Klein PJ, Vierbuchen M, Behnken LJ, Heicke B and Scheidt E: Comparative histological, histochemical, immunohistochemical and biochemical studies on oestrogen receptors, lectin receptors, and barr bodies in human breast cancer. Virchows Arch A Pathol Anat Histopathol 409(2): 127-147, 1986.

20 Kaplan E: Nonparametric estimation from incomplete observations. Journal of the American Statistical Association 53: 281-284, 1958.

21 Mantel N: Evaluation of survival data and two new rank order statistics arising in its consideration. Cancer Chemother Rep 50(3): 163-170, 1966.
22 Partelli S, Inama M, Rinke A, Begum N, Valente R, Fendrich V, Tamburrino D, Keck T, Caplin ME, Bartsch D, Thirlwell C, Fusai $G$ and Falconi M: Long-term outcomes of surgical management of pancreatic neuroendocrine tumors with synchronous liver metastases. Neuroendocrinology 102(1-2): 6876, 2015.

23 Bertani E, Fazio N, Botteri E, Chiappa A, Falconi M, Grana C, Bodei L, Papis D, Spada F, Bazolli B and Andreoni B: Resection of the primary pancreatic neuroendocrine tumor in patients with unresectable liver metastases: Possible indications for a multimodal approach. Surgery 155(4): 607-614, 2014.

24 Bertani E, Fazio N, Radice D, Zardini C, Spinoglio G, Chiappa A, Ribero D, Biffi R, Partelli S and Falconi M: Assessing the role of primary tumour resection in patients with synchronous unresectable liver metastases from pancreatic neuroendocrine tumour of the body and tail. A propensity score survival evaluation. Eur J Surg Oncol 43(2): 372-379, 2017.

25 Givi B, Pommier SJ, Thompson AK, Diggs BS and Pommier RF: Operative resection of primary carcinoid neoplasms in patients with liver metastases yields significantly better survival. Surgery 140(6): 891-897, 2006.

26 Raymond E, Dahan L, Raoul JL, Bang YJ, Borbath I, LombardBohas C, Valle J, Metrakos P, Smith D, Vinik A, Chen JS, Hörsch D, Hammel P, Wiedenmann B, Van Cutsem E, Patyna S, Lu DR, Blanckmeister C, Chao R and Ruszniewski P: Sunitinib malate for the treatment of pancreatic neuroendocrine tumors. $\mathrm{N}$ Engl J Med 364(6): 501-513, 2011.

27 Yao JC, Shah MH, Ito T, Bohas CL, Wolin EM, Van Cutsem E, Hobday TJ, Okusaka T, Capdevila J, de Vries EG, Tomassetti P, Pavel ME, Hoosen S, Haas T, Lincy J, Lebwohl D, Öberg K and RAD001 in Advanced Neuroendocrine Tumors TiTR-SG: Everolimus for advanced pancreatic neuroendocrine tumors. N Engl J Med 364(6): 514-523, 2011.

28 Rindi G, Falconi M, Klersy C, Albarello L, Boninsegna L, Buchler MW, Capella C, Caplin M, Couvelard A, Doglioni C, Delle Fave G, Fischer L, Fusai G, de Herder WW, Jann H, Komminoth P, de Krijger RR, La Rosa S, Luong TV, Pape U, Perren A, Ruszniewski P, Scarpa A, Schmitt A, Solcia E and Wiedenmann B: Tnm staging of neoplasms of the endocrine pancreas: Results from a large international cohort study. J Natl Cancer Inst 104(10): 764-777, 2012.

29 Bergers G, Javaherian K, Lo KM, Folkman J and Hanahan D: Effects of angiogenesis inhibitors on multistage carcinogenesis in mice. Science 284(5415): 808-812, 1999.

30 Pàez-Ribes M, Allen E, Hudock J, Takeda T, Okuyama H, Viñals $\mathrm{F}$, Inoue $\mathrm{M}$, Bergers $\mathrm{G}$, Hanahan $\mathrm{D}$ and Casanovas $\mathrm{O}$ : Antiangiogenic therapy elicits malignant progression of tumors to increased local invasion and distant metastasis. Cancer Cell 15(3): 220-231, 2009.

31 Maione F, Capano S, Regano D, Zentilin L, Giacca M, Casanovas O, Bussolino F, Serini G and Giraudo E: Semaphorin 3a overcomes cancer hypoxia and metastatic dissemination induced by antiangiogenic treatment in mice. J Clin Invest 122(5): 1832-1848, 2012.

32 Hegi ME, Diserens AC, Gorlia T, Hamou MF, de Tribolet N, Weller M, Kros JM, Hainfellner JA, Mason W, Mariani L, Bromberg JE, Hau P, Mirimanoff RO, Cairncross JG, Janzer RC and Stupp R: Mgmt gene silencing and benefit from temozolomide in glioblastoma. N Engl J Med 352(10): 9971003,2005 . 
33 Schraml P, von Teichman A, Mihic-Probst D, Simcock M, Ochsenbein A, Dummer R, Michielin O, Seifert B, Schläppi M, Moch $\mathrm{H}$ and von Moos $\mathrm{R}$ : Predictive value of the mgmt promoter methylation status in metastatic melanoma patients receiving first-line temozolomide plus bevacizumab in the trial sakk 50/07. Oncol Rep 28(2): 654-658, 2012.

34 Preusser M, Charles Janzer R, Felsberg J, Reifenberger G, Hamou MF, Diserens AC, Stupp R, Gorlia T, Marosi C, Heinzl $\mathrm{H}$, Hainfellner JA and Hegi M: Anti-o6-methylguaninemethyltransferase (mgmt) immunohistochemistry in glioblastoma multiforme: Observer variability and lack of association with patient survival impede its use as clinical biomarker. Brain Pathol 18(4): 520-532, 2008.

35 Rodriguez FJ, Thibodeau SN, Jenkins RB, Schowalter KV, Caron BL, O'neill BP, James CD, David James C, Passe S, Slezak J and Giannini C: Mgmt immunohistochemical expression and promoter methylation in human glioblastoma. Appl Immunohistochem Mol Morphol 16(1): 59-65, 2008.

36 House MG, Herman JG, Guo MZ, Hooker CM, Schulick RD, Lillemoe KD, Cameron JL, Hruban RH, Maitra A and Yeo CJ: Aberrant hypermethylation of tumor suppressor genes in pancreatic endocrine neoplasms. Ann Surg 238(3): 423-431, 2003.

37 Arnold CN, Sosnowski A, Schmitt-Gräff A, Arnold R and Blum HE: Analysis of molecular pathways in sporadic neuroendocrine tumors of the gastro-entero-pancreatic system. Int $\mathrm{J}$ Cancer 120(10): 2157-2164, 2007.
38 Ekeblad S, Sundin A, Janson ET, Welin S, Granberg D, Kindmark H, Dunder K, Kozlovacki G, Orlefors H, Sigurd M, Oberg K, Eriksson B and Skogseid B: Temozolomide as monotherapy is effective in treatment of advanced malignant neuroendocrine tumors. Clin Cancer Res 13(10): 2986-2991, 2007.

39 Welin S, Sorbye H, Sebjornsen S, Knappskog S, Busch C and Oberg K: Clinical effect of temozolomide-based chemotherapy in poorly differentiated endocrine carcinoma after progression on first-line chemotherapy. Cancer 117(20): 4617-4622, 2011.

40 Schmitt AM, Pavel M, Rudolph T, Dawson H, Blank A, Komminoth P, Vassella E and Perren A: Prognostic and predictive roles of mgmt protein expression and promoter methylation in sporadic pancreatic neuroendocrine neoplasms. Neuroendocrinology 100(1): 35-44, 2014.

41 Cives M, Ghayouri M, Morse B, Brelsford M, Black M, Rizzo A, Meeker A and Strosberg J: Analysis of potential response predictors to capecitabine/temozolomide in metastatic pancreatic neuroendocrine tumors. Endocr Relat Cancer 23(9): 759-767, 2016.
Received March 16, 2017

Revised April 7, 2017

Accepted April 11, 2017 